\title{
APONTAMENTO SOBRE A AGROVILA LEONARDO D'VINCI E A REINVENÇÃO DE SEU COTIDIANO APÓS A CONSTRUÇÃO DA HIDRELÉTRICA DE BELO MONTE $^{1}$
}

\author{
Pedro Sérgio Santos da Costa ${ }^{2}$ \\ Cesar Martins de Souza ${ }^{3}$
}

\begin{abstract}
RESUMO
A Rodovia Transamazônica e a Usina Hidrelétrica Belo Monte (UHBM) representam muito mais do que apenas duas obras de grande porte do Governo Federal, elas são concretizações de um modo de pensar desenvolvimentista vigente desde a década de 1950 no Brasil. Entre a rodovia e a usina há um elo sócio-histórico, geográfico e metafórico, a Agrovila Leonardo D'Vinci (ALDV), no distrito do município de Vitória do Xingu, estado do Pará. Este artigo tem por objetivo apresentar uma primeira análise do custo social do desenvolvimentismo no cotidiano dessa comunidade, uma vez que esta surge como resultado da grande rodovia e "renasce", quarenta e dois anos depois, no contexto da UHBM. Para tanto, foram realizadas entrevistas com pioneiros da localidade, bem como pesquisa documental acerca do tema proposto. Os resultados apontam para a ocorrência de profundas transformações sociais aceleradas pela construção do empreendimento hidroelétrico, possibilitando questionar os "grandes projetos" na região amazônica e suas implicações sociais.
\end{abstract}

Palavras-chave: Agrovila D’Vinci; Hidrelétrica Belo Monte; Impactos sociais.

\begin{abstract}
The Transamazônica road and the Belo Monte Hydroelectric Power Plant (UHBM) represent much more than just two Mega projects of the Brazilian Federal Government, they turned a desire plan of a developmental way to the region into reality. It was thought since the 1950 s in our nation. Among many others, there is a socio-historical, geographical and metaphorical link to the Leonardo D'Vinci agricultural village (LDAV), a district of Vitória do Xingu municipality, in the state of Pará. That is whay, this article aims to analyze the social cost of developmentalism process in the daily life of this community since it was settled as a result of the enormous Transamazônica road and "reborn" after forty-two years later, in the context of UHBM. In order to verify its impacts, interviews with local pioneers were carried out, as well as detailed documentary research was done. In addition to a bibliography research about the proposed theme was performed as well. The results of all these studies point to the occurrence of deep and accelerated social transformations mostly related from both direct and indirect cases of omissions caused by Belo Monte hydroelectric project. It is expected that the results of this present study contributes to further researches to better understand and describe the study of "Mega projects" in the Amazon area as well as studies of developmentalism impacts and its costs to the Amazon rainforest and its people.
\end{abstract}

Keywords: Daily life, Developmentalism; Social Transformations; D'Vinci agricultural village ; Belo Monte Hydroelectric Plant.

\footnotetext{
${ }^{1} \mathrm{O}$ exposto neste artigo compõe parte da dissertação de mestrado vinculado ao Programa de Pós-graduação em Linguagens e Saberes na Amazônia - PPLSA, intitulada "O Custo Social do Desenvolvimentismo: o caso da Agrovila Leonardo D’Vinci em Vitória do Xingu-PA, no contexto de Construção da Usina Hidrelétrica Belo Monte.".

${ }^{2}$ Mestrando em Linguagens e Saberes da Amazônia pelo PPLSA. Contato: pedrosergio@ufpa.br.

${ }^{3}$ Doutor em História pela Universidade Federal Fluminense, Mestre em Antropologia pela UFPA, Licenciado e Bacharel em História pela UFPA. Professor Adjunto da Universidade Federal do Pará (UFPA), desenvolvendo atividades docentes no Programa de Pós-Graduação em Linguagens e Saberes da Amazônia/UFPA. E-mail: <cesar@ufpa.br>.
} 


\section{INTRODUÇÃO}

A vida cotidiana de uma comunidade, como bem sustentou Certeau et al. (2008), seja um bairro, uma agrovila ou equivalente, se organiza por meio da articulação de pelo menos duas dimensões, os comportamentos e os benefícios simbólicos. Os comportamentos se manifestam nos contatos interpessoais, nos modos de vestir, nos códigos de cortesia, bem como nos espaços frequentados ou abandonados. Os benefícios simbólicos se traduzem nas expectativas do que se pretende auferir por conta dessa ou daquela maneira de se comportar no interior dessa comunidade. Assim, a vida cotidiana se apresenta como uma espécie de convenção coletiva tácita historicamente construída em prol de benefícios simbólicos. Por isso, tais estruturas não se adaptam a mudanças abruptas já que a aquisição do reconhecimento por parte de seus atores leva tempo e esforço, o que diante de rápidas transformações tudo tem que ser reconstruído (CERTEAU et al., 2008, p. 37, 48).

Tendo em conta a reflexão anterior, pergunta-se: o que ocorreria na vida cotidiana de uma comunidade majoritariamente agrícola se, de fato, tais transformações se efetivassem? Tudo indica ser este o caso da Agrovila Leonardo D’Vinci ${ }^{4}$, um distrito do município de Vitória do Xingu, no estado do Pará. Este artigo busca estudar a relação existente entre as profundas mudanças sociais na vida cotidiana surgidas na ALDV e a construção da Usina Hidroelétrica Belo Monte. Esta comunidade surgiu no contexto de um grande projeto desenvolvimentista, a Rodovia Transamazônica, em 1972 e, desde então, nas últimas quatro décadas não havia experimentado um grau de alterações sociais tão radicais quanto as que estão ocorrendo desde o final do ano de 2012 até 2018.

$\mathrm{Na}$ análise da comunidade em causa relativamente aos impactos produzidos por Belo Monte parece evidenciar-se o que Morim (2005) denomina de homogeneização da consciência, como resultado de uma erosão das virtudes humanas e cívicas (MORIM, 2005, p.164), para além de um simples afastamento e separação gradual da natureza. Daí a razão da quase sempre antagônica relação entre desenvolvimento e usufruto sustentável da natureza.

Exemplo dessa problemática é a retomada, na última década, de grandes Projetos Federais peculiares implementados nos mais diversos lugares do país, sobretudo, na região amazônica. Dentre estes, destaca-se aqui um que está em plena execução e que entre outras

\footnotetext{
${ }^{4}$ Embora a história do nome da agrovila revele ser uma homenagem ao polímata italiano "Leonardo di Ser Piero da Vinci", o nome oficial dela é este mesmo: "Leonardo D'Vinci”. A comunidade é um distrito do município de Vitória do Xingu e está localizada a 60 km deste e a 18 quilômetros da cidade de Altamira, sudoeste do Pará.
} 
questões tem causado notável metamorfose social nas comunidades no entorno de seu raio de ação - a construção da Usina Hidroelétrica Belo Monte.

Nesse sentido, para que se evidencie a proposta de indagar a orientação do desenvolvimentismo, concretizado na UHBM, como causa de transfiguração social nesta localidade, considerou-se pertinente sondarmos, sobretudo, fenômenos da dimensão econômica e social dentre o rol de ocorrências ali ainda em vigor. A exposição das problemáticas contidas nessas duas dimensões será suficiente para nosso objetivo, visto concentrarem as mais amplas, profundas e céleres transformações nessa comunidade.

\section{A TRANSAMAZÔNIA E O “NASCIMENTO” DA AGROVILA D’VINCI}

Há quarenta e oito anos, o povo brasileiro vivenciava um momento singular de sua história, ao mesmo tempo em que celebrava a euforia do tricampeonato mundial de futebol. Era o auge do regime militar, no tocante a economia e popularidade, ao mesmo tempo em que, nos bastidores, torturas eram praticadas nos recônditos militares (FICO, 2001. p. 21). Ao pé do tronco do que antes era uma castanheira ${ }^{5}$, no dia nove de outubro daquele ano, em plena floresta amazônica, o então Presidente da República o General Emílio Garrastazu Médici inaugura o marco inicial de um ambicioso projeto nacional com os dizeres registrados numa placa onde até hoje se pode ler: "Nesta margem do Xingu, em plena selva Amazônica, o Sr. Presidente da República dá inicio à construção da Transamazônica, numa arrancada histórica para a conquista e colonização deste gigantesco mundo verde".

Com este ato deu-se início ao projeto de integração e desenvolvimento da Amazônia, no contexto do governo militar. A construção da rodovia Transamazônica (BR-230) era representativa de novos tempos, e juntamente com ela outras estavam em curso, como a Perimetral Norte, Pará-Maranhão (BR-316), Manaus-Porto Velho (BR-319) e CuiabáSantarém (BR-163). A imponente BR-230 iria, então, surgir de dois locais, João Pessoa/PB e Recife/PE para depois convergir em Picos/PI, passaria pelo Maranhão, Pará, Amazonas até Boqueirão da Esperança no Acre. Um dos objetivos para justificar este traçado era ligar o Oceano Atlântico ao Pacífico, conectando-se ao Peru.

\footnotetext{
5 Por ocasião da inauguração do marco inicial da Construção da Transamazônica uma castanheira de aproximadamente 50 metros de altura foi cortada e no tronco do que dela restou foi pregada uma placa de bronze com a inscrição mencionada. Em 2013 o então Prefeito, em exercício, do município de Altamira, Domingos Juvenil Nunes de Sousa, manda realizar uma restauração deste marco inaugural. Na oportunidade o antigo tronco, já apodrecido, é trocado por um similar (de menor proporção) e a placa antes incrustrada no antigo madeiro é colocada ao lado em um suporte de concreto.
} 
Integração, Desenvolvimento e Planejamento se tornaram "mantras" nacionais. Integração, naquele contexto, era colocar a Amazônia em conexão com as demais regiões do país. Desenvolvimento, por sua vez, dizia respeito, não somente à ocupação do imenso vazio demográfico, mas especialmente à criação de empreendimentos agroindustriais e agropecuários, comércio e, como condição fundamental, o povoamento. O objetivo mais urgente, porém, que subjazia nestes projetos governamentais militares era o de amenizar as pressões advindas das tensas insatisfações sociais, ligadas a questões agrárias, que ocorriam tanto no Nordeste como no Sul do país, para isso sendo necessário despovoar aquelas regiões com excesso de mão-de-obra e povoar as que estavam desocupadas. Esta era a base da célebre frase pronunciada por Médici: "Uma terra sem homens para homens sem terra"6.

A construção da rodovia destinava-se a resolver diversos problemas: defesa do território nas regiões de fronteira, aumento da produção agroindustrial e agropecuária em áreas antes pouco produtivas, integração destas regiões ao resto do país e equilíbrio populacional entre regiões com demografia densa e as consideradas como vazios demográficos. Há que ter em conta ainda os interesses internacionais, como o dos Estados Unidos da América, que chegaram a financiar a mobilização de trabalhadores para a Amazônia, pagando através do Rubber Development Corporation/RDC - mantido com capital da indústria norte americana - "ao governo brasileiro cem dólares por cada trabalhador mobilizado e entregue na Amazônia" (UMBUZEIRO, 2012, p.194).

As ações de propaganda governamental do empreendimento ofereciam enganadoramente uma terra de sonhos e oportunidades, cujos enunciados prediletos, entre outros, eram: "Brasil, ame-o ou deixe-o", "Integrar para não entregar", e a já citada "Uma terra sem homens para homens sem terra". Milhares de famílias de diversas partes do país afluíram para o Novo Eldorado ${ }^{7}$. O projeto de colonização dirigida de rede urbana hierarquizada previa instalar agrovilas a cada $10 \mathrm{~km}$, dentre estas, a cada $50 \mathrm{~km}$ uma agrópolis, às quais estariam subordinadas quatro agrovilas subjacentes, e finalmente a cada $150 \mathrm{~km}$ seria instalada uma Rurópolis responsável pela jurisdição de duas agrópolis. As agrovilas abrigariam entre 50 e 64 casas, escola de primeiro grau, armazém, farmácia, posto

\footnotetext{
6 "Amazônia, horizonte do nordestino". Acervo da Folha de São Paulo, 9 de outubro de 1970. Disponível em: $<$ https://acervo.folha.com.br/leitor.do?numero=3806\&keyword=terra\%2Chomens\&anchor=4370099\&origem=b usca>. Acesso em 02 de abr. de 2017.

7 "Amazônia vive dias históricos" este é o título duma reportagem de jornal na qual o então Governador do Pará: Alacid da Silva Nunes afirma que (o início da construção da Transamazônica) "A Amazônia inteira vive um dos mais belos momentos de sua história..." e continua com uma lista de adjetivos elogiosos ao empreendimento e ao Presidente Médici. O Estado de São Paulo: Páginas da Edição de 10 de outubro de 1970 - Pág. 46. Disponível em: <http://acervo.estadao.com.br/pagina/\#!/19701010-29298-nac-0046-999-46-not〉. Acesso em: 26 de janeiro de 2018 .
} 
de saúde e uma capela, cabendo a cada núcleo familiar 100 hectares de terra. As agrópolis iriam acomodar posto de gasolina, escola secundária, comércio e olaria e um contingente máximo de dois mil e quinhentos habitantes para quinhentas casas. A responsabilidade pelo cadastramento, seleção e mobilização das famílias no Nordeste coube ao Serviço Especial de Mobilização de Trabalhadores para a Amazônia (SEMTA) com sua sede em Fortaleza/CE (UMBUZEIRO, 2012). À medida que as famílias chegavam, o "coração" da floresta era rasgado por centenas de grandes máquinas, como mostra a figura adiante logo nos primeiros quilômetros de derrubada da densa mata amazônica.

Mais precisamente no perímetro compreendido entre as cidades de Altamira e Itaituba surgiram a agrópolis Brasil Novo (a quarenta e seis quilômetros do marco inaugural da estrada, em Altamira) e a rurópolis Presidente Médici (a uma distância de noventa quilômetros do mesmo marco). Dentre as agrovilas merece destaque a Agrovila Leonardo D’Vinci ${ }^{8}$, que já no início de sua implantação contou com pavimentação asfáltica em algumas ruas. Brasil Novo e Medicilândia criadas como núcleos de colonização da rodovia, na década de 1970, se tornaram municípios no fim do século XX.

O cenário até este ponto dava conta de que, embora o projeto de abertura da estrada tenha sido completado, perfazendo mais de quatro mil quilômetros abertos (parou, todavia, em Lábrea/AM, à distância de 687 quilômetros do ponto final almejado), pouco mais de dois mil quilômetros foram asfaltados. Além disso, em termos de análise comparativa entre assentamento pretendidos versus realizados não somente a ineficácia fez-se real como a própria quantidade almejada era surreal, Contini (1976) revela que no Primeiro Plano de Nacional de Desenvolvimento havia a programação para assentar entre os anos de 1971 e 1974 em torno de 70.000 famílias, cifra depois alterada (por meio do Decreto 67.557 de 1970) para 100.000. Porém, em novo e mais modesto planejamento os números já se encontravam mais ajustados à realidade, de modo que a quantidade pretendida passou para 11.200 famílias, ainda assim, mesmo com essa gritante diminuição de meta, até 1974 o número de famílias assentadas só havia alcançado 5.717, ou seja, menos de 50\% da meta ajustada e 5,7\% da inicial (CONTINI, 1976, p. 146 - 149). Estas, contudo, são apenas algumas evidências de

\footnotetext{
${ }^{8}$ Localizada a $63 \mathrm{~km}$ da sede do município (Vitória do Xingu) e a $18 \mathrm{~km}$ de Altamira, conta atualmente com aproximadamente 365 famílias e 830 residências, até final de 2015, segundo contagem da Associação de Moradores da Agrovila. A história do nome da agrovila é incerta uma vez que o cidadão mais antigo da comunidade atribui o nome dela como sendo uma homenagem por parte de um "síndico temporário do INCRA na vila", nos tempos de assentamento, e cujo pintor preferido era o polímata italiano. O mistério aumenta quando se considera o depoimento de uma professora da escola local, para ela o nome da agrovila é proveniente de estrangeiros europeus que por ali se fixaram por algum tempo.
} 
problemas na concretização do empreendimento - dentre outros - como, por exemplo, a quantidade de agrovilas que continuam “de pé”, que são apenas vinte

Este é o cenário de surgimento da Agrovila Leonardo D’Vinci, no epicentro do que era muito mais que uma estrada que levaria de um lugar para outro, ou de um oceano a outro, uma vez que se apresentava como a solução para o flagelo da seca que assolava o Nordeste; integração de território; escoadouro de produção para o Pacífico enfim, a solução para muitos problemas nacionais conforme propagandeava o governo.

\section{O COTIDIANO NA AGROVILA}

A Agrovila Leonardo D'Vinci teve em sua gênese o assentamento de aproximadamente 60 famílias com um total aproximado de 250 habitantes. É o que relata, em entrevista, o primeiro morador da agrovila e que continua a residir na localidade, o senhor Catarino ${ }^{9}$ :

[...] a gente chegou aqui em dezembro de 1971, eu e a minha esposa [Dona Serena], e fomos levados pro João Pezinho. Depois de uns dias eu vim pra cá [para a Agrovila D'Vinci] e ela [a esposa] ficou lá. Eu fui atrás de serviço no INCRA, não conseguia ficar parado, e eles me colocaram na equipe que ia construir as casas do D’Vinci. Quando a gente chegou aqui não tinha nada, só juquira [mato denso], aí nós esperamos uma semana pro trator chegar e limpar a área, daí a primeira coisa que a gente fez foi um barracão bem grande. No barracão tinha a COBAL [Companhia Brasileira de Alimentos] que ficava bem no meio, num canto ficava uma farmácia e no outro canto uma venda de ferramentas [...] depois a gente começou a construir as casas, três conjuntos de 18 casas, e ia chegando mais e mais gente, tinha vez que ficavam duas e até três famílias na mesma casa até que ficasse pronta as outras (CATARINO, 2016).

O mesmo interlocutor, quando perguntado acerca do que semeavam na época, respondeu: "Olha moço, naquela época além de tudo que eles (o INCRA) davam pra gente, a EMATER ainda ensinava a plantar e se a terra fosse boa de cacau (Theobroma cacao), o BASA (Banco da Amazônia S/A) fazia empréstimo pra gente"10. Na oportunidade ele recordou ainda que os contratos de empréstimo estipulavam cinco anos de carência para começar a pagar o mútuo. Mas a instituição bancária exigia uma garantia que, para o colono da época, só podia ser dada por meio de hipoteca do lote, visto ser o único bem de razoável valor para o banco. Acresce que este possuía de alguns tomadores, além da hipoteca, um

\footnotetext{
${ }^{9}$ Entrevista concedida em 06 de setembro de 2016. Observamos que, como forma de resguardar a identidade dos interlocutores seus nomes, foram substituídos por pseudônimos.

${ }^{10}$ CATARINO, Ibidem.
} 
fiador; assim, para satisfazer esta condição, os agricultores tomadores de empréstimo tornavam-se fiadores uns dos outros. Deste modo:

\begin{abstract}
[...] um colono endossava pro outro pra tirar o dinheiro, aí como eu não endosso pra ninguém eu fui lá com o gerente e disse que não endossava pra ninguém, daí perguntei eu tiro ou não tiro o dinheiro? Ele me disse pra preencher um papel e pegar o documento da terra aí eu consegui [...] não foi fácil por que a EMATER tinha que assinar também, aí tinha que dá uma ponta ${ }^{11}$ (propina) pra eles, tinha uns que dava, mas eu não dei não, outros deram, eu não. Eu nunca dei o meu beiço pros outros grampearem [...] os colono chegava lá (na EMATER) e diziam: seu doutor libera meu dinheiro, meus filhos estão passando fome, isso me doía por dentro sabe $!^{12}$. (CATARINO, 2016).
\end{abstract}

Segundo este pioneiro da ALDV, foi dessa maneira que alguns conseguiram produzir culturas de arroz (Oryza sativa), milho (Zea mays), feijão (Phaseolus vulgaris) e cacau (Theobroma cacao), uma vez que o salário dado durante seis meses pelo INCRA não permitia investir na terra. Nos primeiros anos, a produção era vendida quase que exclusivamente à CIBRAZEM $^{13}$, mas depois os produtos passaram a ser transacionados para qualquer comerciante que os comprasse em Altamira. Além do cultivo para venda ainda havia, entre muitos moradores, o hábito de usar os quintais de suas casas urbanas para o plantio de subsistência de abóbora (Cucurbita pepo), alface (Lactuca sativa), feijão (Phaseolus vulgaris), milho (Zea mays), pimentão (Capsicum annuum Group), cenoura (Daucus carota), macaxeira (Manihot esculenta), tomate (Solanum lycopersicum), cana-de-açúcar (Saccharum officinarum), batata (Solanum tuberosum), entre outros. Quanto às frutas, havia o cultivo, sobretudo, de açaí (Euterpe oleracea), cupuaçu (Theobroma grandiflorum), graviola (Annona muricata), banana (Musa), cacau (Theobroma cacao) e manga (Mangifera indica). Era também comum a criação de pequenos animais como porco (Sus scrofa domesticus), galinhas (Gallus gallus domesticus ) e patos (Anas platyrhynchos domesticus).

Dentre outras estratégias de sustento, o trabalho em roças e fazendas das redondezas, aliado à agricultura familiar para consumo próprio e se possível venda do excedente na cidade de Altamira, era a mais recorrente e comum àquelas famílias. Neste sentido, os que persistiam em se estabelecer na ALDV se reorientavam, adaptaram e aprenderam a fazer daquele local de condições inóspitas o seu novo domicílio.

O lugar passou a ser considerado mesmo como um "lar", em particular no que concerne à segurança, "estabilidade” econômica e mútua confiança entre os moradores, em

\footnotetext{
${ }^{11}$ Grifo nosso.

12 Ibidem.

13 Da fusão da Companhia Brasileira de Armazenamento (CIBRAZEM) e COBAL foi criada a Companhia Nacional de Abastecimento (CONAB), por intermédio da Lei nº 8.029, de 12 de abril de 1990.
} 
suma, uma sociabilidade de contornos pacíficos. "Polícia? A gente nunca precisô aqui, só uma vez nesses tempo todo", assevera dona Serena ${ }^{14}$, a esposa do senhor Catarino ${ }^{15}$. Num cenário como este não é difícil imaginar as pessoas conversando à porta de suas casas mesmo depois de escurecer, e é o que acontecia no cotidiano antes de Belo Monte. É o que revela nossa interlocutora que, como "não gostava de sair muito"16 ficava sentada na frente de sua casa a observar o movimento das pessoas nas ruas, narra que não havia praças de lazer, mas ao menos um jogo de futebol em campos improvisados era possível avistar ao cair da tarde. Outros moradores, como o seu marido, aliavam a este cenário um rádio "ao pé do ouvido" que dava as notícias de Belém e transmitia o programa evangélico "A Voz do Cenáculo" da instituição religiosa à qual ele se declarava membro.

Segundo estes relatos, este parece ter sido o cenário mais regular na vila por um tempo considerável, sem esquecer todas as dificuldades que estes moradores enfrentaram na sua chegada à agrovila. Também não pode ser negligenciado que os que venceram as adversidades dos primeiros anos foram se adaptando a um novo modo de vida, que possibilitou colher benesses da nova realidade. Além das que já foram citadas, os entrevistados lembram com nostalgia e orgulho o tempo em que não se ouvia falar em prostituição infantil, furtos, drogas, fome ou aflições semelhantes em sua comunidade. Sobre isso, dona Serena arremata: “[...] ninguém mexia com ninguém, esse negócio de droga, eu não sei, de onde sai isso, o senhor sabe? Meus filhos nunca fizeram isso".

Quatro décadas se passaram e esta comunidade foi experimentando mudanças nos mais variados âmbitos, embora num ritmo que poderíamos chamar de não traumático. Em 2012, ao completar quarenta e dois anos, era hora de experimentar, querendo ou não, um novo recomeço, pois chegava às suas portas mais um "faraônico" projeto de governo, desta vez, dito "democrático".

\section{HIDRELÉTRICA BELO MONTE E A REINVENÇÃO DO COTIDIANO LEODAVINCIANO}

Logo no início do processo mobilizatório de construção da hidrelétrica, parece ter havido uma melhoria financeira das famílias leodavincianas ${ }^{17}$, mas tratava-se de um

\footnotetext{
${ }^{14}$ Entrevista concedida em 6 de setembro de 2016.

15 CATARINO, op. cit.

${ }^{16}$ SERENA, op. cit.

${ }^{17}$ É um gentílico constantemente usado pelos moradores da ALDV para se autodesignarem como pertencentes à Vila.
} 
movimento apenas momentâneo, pois, os indivíduos economicamente ativos dessas famílias, ao tornarem-se empregados do Consórcio Construtor Belo Monte $(\mathrm{CCBM})^{18}$ ou de uma de suas subsidiárias (subcontratadas) prestadoras de serviços, tiveram que abandonar a continuidade de outras atividades tradicionais de manutenção e provisão. Após o período de contratações e de "esfriamento" das obras, começava o de demissões em massa e, dentre estes estavam muitos trabalhadores da comunidade. Após serem despedidos não puderam mais retornar aos seus antigos afazeres e modos de sustento, uma vez que não tinham mais a terra para plantar nem os antigos empregos nas fazendas das redondezas. Para aguçar o problema, o aluguel que lhes garantia um complemento de renda também já não existia. Registre-se ainda que, no auge de uma prática mercadológica até então não experimentada localmente, a da especulação imobiliária, alguns mais otimistas realizaram empréstimos bancários, tendo em vista a edificação de imóveis para alugar, dando como garantia seu lote rural ou o urbano com a casa construída.

O resultado econômico imediato foi a proliferação substancial de desemprego, famílias endividadas, sem terra para plantar nem mesmo itens alimentícios diários mínimos, alguns correndo o risco de perder suas casas e outros, que já viviam há mais de vinte anos na agrovila, viram-se rapidamente obrigados a sair à procura de emprego adaptado às suas supostas "novas habilidades" adquiridas por meio de treinamento no centro de capacitação da hidrelétrica. Some-se a isto a alta de preços dos alimentos, bens de necessidade básica e a barganha nas questões de habitação que se alastrou na comunidade e municípios próximos. No grupo social em tela, houve, e há, até mesmo casos de famílias inteiras que não poucas vezes se encontraram em total ausência de alimentos, permanecendo nessa situação por dois dias ou mais conforme revela o senhor $\mathrm{Cunha}^{19}$, presidente da associação de moradores da vila e prestador de serviços à Prefeitura de Vitória nessa comunidade. "Riqueza num dia, fome no outro" insiste e ameaça se tornar um triste adágio daquela comunidade.

Mesmo se considerássemos "apenas" esses fatores, eles já seriam decerto suficientes

\footnotetext{
18 A Hidrelétrica Belo Monte teve um custo inicial orçado em $\mathrm{R} \$ 16$ bilhões, porém foi leiloada por $\mathrm{R} \$ 19$ bilhões e finalmente financiada por R $\$ 28$ bilhões. Desse total, pelo menos R \$ 13,5 bi foram emprestados pelo BNDES ao Consórcio Norte Energia, vencedor (contra o Consórcio Belo Monte Energia - encabeçado pela Construtora Andrade Gutierrez Participações S/A) do leilão (realizado em 20 de abril de 2010) cuja formação inicial contava com nove instituições entre estatais e empresas de capital totalmente privado, eram elas: Chesf (Companhia Hidroelétrica do São Francisco), com 49,98\%; Construtora Queiroz Galvão S/A, com 10,02\%; Galvão Engenharia S/A, com 3,75\%; Mendes Junior Trading Engenharia S/A, com 3,75\%; Serveng-Civilsan S/A, com 3,75\%; J Malucelli Construtora de Obras S/A, com 9,98\%; Contern Construções e Comércio Ltda, com 3,75\%; Cetenco Engenharia S/A, com 5\%; Gaia Energia e Participações, com 10,02\%. Disponível em: < http://www1.folha.uol.com.br/mercado/2010/04/723488-consorcio-liderado-por-chesf-e-queiroz-galvao-venceleilao-de-belo-monte.shtml>. Acesso em 03 de maio de 2018.

${ }^{19}$ Entrevista foi concedida em 15 de setembro de 2016.
} 
para gerar várias atribulações sociais e econômicas, no entanto, constatam-se também outras situações que devem ser analisadas conjuntamente para que se possa compreender com mais precisão as dinâmicas socioconjunturais da agrovila.

Nesse sentido, deve-se pontuar que muitos pais, por conta dos diferentes turnos de expediente e também pela distância dos postos de trabalho da hidrelétrica, saíam ainda de madrugada para trabalhar e deixavam sozinhos os seus filhos que em alguns casos tinham nove anos ou menos de idade, retornando somente à noite, em geral por volta das dezenove horas. Estes pais, portanto, passaram a sair de casa de madrugada, deixando sozinhos os filhos menores por um período de até quinze horas em pelo menos cinco dias da semana.

Pontue-se que estava em curso uma forte atração exercida pela propaganda das empresas contratantes, ao apresentarem seus pacotes de benefícios e vantagens, pareceu exercer uma força irresistível sobre os que de tais notícias tomavam conhecimento. Uma oportunidade aparentemente "imperdível" de ganhar mais dinheiro do que de costume nos trabalhos na vila e redondezas, mas em pouco tempo o cenário que se estabeleceria se encarregaria de mostrar uma outra face não prevista por estes cidadãos.

Ao que parece a sociabilidade desse grupo social de cidadãos gozava de uma relação de confiança existente entre os moradores que não enfrentavam problemas com violência, cada vez mais comum nas grandes cidades. Nesse ambiente seria, portanto, bastante natural os pais se sentirem mais tranquilos quando ficavam fora de casa para trabalhar. Nessa perspectiva, um comportamento comum de muitos era sentirem-se à vontade para deixar os filhos sozinhos por tantas horas tendo, em alguns poucos casos, somente uma ou outra pessoa, em geral algum vizinho, que os observava a distância e ficava de sobreaviso em caso de alguma emergência.

Não obstante essas questões familiares, deve-se ter em mente que por conta dos altos preços de aluguéis e alimentos na cidade de Altamira, a cidade mais próxima da vila - no auge das contratações de funcionários pela $\mathrm{CCBM}$, mais de mil e trezentas pessoas, sobretudo homens solteiros empregados da usina, assentaram morada na agrovila num movimento migratório que durou aproximadamente um ano. A agrovila se tornava muito atraente a esta leva de trabalhadores, pois além de ter os preços desses dois itens mais baratos que naquele município, também contava com uma posição geográfica ainda melhor que ele no que se refere a distância dos canteiros de obras da hidrelétrica. Com efeito, a distância entre Altamira e um dos principais canteiros de serviço da usina hidrelétrica, o Sítio Pimental, é de aproximadamente quarenta quilômetros, enquanto a ALDV dista dezoito quilômetros menos, uma vez que se encontra no exato caminho entre a referida cidade e a Usina. 
Nesse contexto, a escassez de policiamento na agrovila resultaria em não fornecimento das melhores condições para a prevenção da violência. As consequências do encontro abrupto de todos esses elementos no cotidiano leodavinciano resultou em um fenômeno sinérgico, no qual a junção das partes é maior que o todo em seus efeitos, ou seja, se tivessem surgido ao longo de um período mais ou menos longo ou se ao menos não fossem simultâneos talvez a comunidade da ALDV tivesse tempo suficiente para a construção de estratégias eficazes de resistência e adaptação, mas como se vê, esse não foi o caso. Daí o surgimento de diversos impactos, dos quais alguns se encontram mitigados dentre outros ainda em curso, contudo, por meio da presente ponderação, passamos a ressaltar as seguintes contrariedades.

Com base, sobretudo, nos relatos de agentes sociais do Centro de Saúde, verificou-se o despontar de um distanciamento das relações de confiança e intimidade familiares. Esse arredamento parece ter origem parcialmente em um fenômeno global que afasta os familiares das conversas ao fim do dia, brincadeiras, passeios e encontros semanais frente ao acesso às tecnologias voltadas à internet e bem assim às redes sociais, dentre muitas outras possibilidades. Vemos, porém, como fundamental ponto de influência nesse processo, o comportamento mais ligado diretamente aos longos e diários períodos de afastamento dos pais, fazendo com que os filhos procurassem companhia fora da família.

Com os novos cenários após a construção da UHBM, a agrovila passou a vivenciar uma nova realidade, como surgimento ${ }^{20}$ de furtos e arrombamentos de casas. Trata-se isto de um fator que surgia na atual década e que gerou transformações nas paisagens da vila, nos diversos donos de imóveis e que tem ajudado a acelerar mudanças na feição da paisagem urbana da vila, medidas estas que se manifestam pelo levantamento de muros de alvenaria “coroados" com cercas elétricas sobre si e em torno das moradias, onde antes não havia nem mesmo cogitação nesse sentido.

Por ocasião de um desses arrombamentos, houve até mesmo disparos de tiros contra o(s) assaltante(s) por parte de um morador, que, por razões óbvias, não nos foram revelados nome ou endereço. Por sorte, ninguém se feriu, ou nas palavras do entrevistado, "o cabra escapou, seu moço".

Nas portas e nas praças já não se sentam mais, andar nas ruas à noite tornou-se perigoso. Tornaram-se prisioneiros em seus locais de moradia, um fenômeno nada estranho em cidades grandes e violentas, mas inédito nesta agrovila. De certo modo, todo esse cenário tem levado à proliferação do sentimento de insegurança e quase impotência, embora alguns

\footnotetext{
${ }^{20}$ Não existia esse tipo de ocorrência antes da hidrelétrica.
} 
moradores insistam em afirmar ser a ALDV um lugar ainda tranquilo para se viver.

A respeito do que se revelou anteriormente, vale a pena citar Herrera (2012) quando argumenta que, à medida que se vai alterando o contexto e os meios e relações de produção, tanto o ambiente quanto a sociedade vão se degradando, sendo este um resultante do que o autor denomina de "a ditadura do dinheiro" e que a nosso ver tem uma afinidade com o desenvolvimentismo:

A ditadura do dinheiro ${ }^{21}$ faz com que o capital se movimente geograficamente, explorando as oportunidades abertas pelas vantagens locacionais. Essa mobilização, bem como a desorganização e degradação caracterizam o caos para as sociedades que são subjugadas nas relações e para o capital torna-se uma das formas de impor a sua lógica na reorientação do funcionamento do território (HERRERA, 2012, p.2, $61)$.

Geograficamente o capital se faz presente na região da Volta Grande do Xingu e proximidades cuja localização, como bem disse Herrera, lhe apresenta, nesse momento, vantagens financeiras. O caos, contudo, exercido pela desorganização e degradação é o que tem restado às regiões subjugadas por sua lógica. Esse, pelo que até aqui já foi registrado, parece ser o caso de D’Vinci, mas nem sempre isso é tão cristalino, em muitos casos as avaliações são fragmentadas e excessivamente pontuais, daí talvez as dificuldades de organização, defesa e resistência, situação vivida na comunidade.

\section{CONSIDERAÇÕES FINAIS}

O pensamento desenvolvimentista propalado pelo Governo Federal na região e calorosamente abraçado por muitos moradores é uma ideologia presente, sobretudo após as obras de construção da UHBM. E no uso de suas forças segue-se a execução de seus projetos de maneira que pouco ou nada contribuem ou se importam com a mitigação dos impactos decorrentes nas comunidades abrangidas por seus atos.

“Após as obras, os funcionários se retiram e a economia dos municípios se desestrutura novamente em virtude da perda de mercado consumidor. Fenômeno este que tem sido denominado Ciclo Boom-Colapso" (BEZERRA et al., 2014). É isso mesmo que revela Herrera (2013) ao apontar que desde o ano de 2011 se registrou um crescimento vertiginoso da população no município de Altamira "em tese, constituído pela demanda por mão de obra por parte das empreiteiras ao iniciarem as obras", saindo de aproximadamente $100 \mathrm{mil} \mathrm{em}$

\footnotetext{
${ }^{21}$ Grifo nosso.
} 
2010 para aproximadamente 146.224 habitantes nos primeiros meses de 2012 (HERRERA 2013, p.134). Trata-se de um crescimento de quase 50\% da população urbana, gerador de diversos problemas econômicos, de segurança pública e sociais nesse município. Desse total, entre 2014 e 2015, cerca de 1300 se deslocaram para a ALDV, perfazendo um acréscimo populacional de aproximadamente $125 \%$ nessa agrovila em pouco mais de um ano.

Diante do quadro exposto e olhando também para toda a saga dos pioneiros nos primórdios da ALDV, observamos que, na presente década, os moradores passaram a conviver com incertezas, inseguranças, violências e sérios problemas econômicos e sociais. As modificações no cotidiano dos moradores ocorreram com intensidade e profundidade, agindo corrosivamente no interior dos lares, na deterioração dos hábitos culturais, laços familiares, cenário econômico, entre outras esferas, transtornando as suas vidas.

Todavia, se uma parcela significativa desse lugar vê com angústia as ocorrências dos últimos anos, ligando-as ao empreendimento hidrelétrico, outra não vislumbra essa relação. Tal situação demonstra que, dentro de um mesmo contexto, uns aparentemente enxergam modernidade e progresso e quase nenhuma contrariedade, enquanto outros percebem uma maior intensidade dos desajustes causados por essa obra. Certo mesmo é que percebendo ou não tais relações, a população leodavinciana tem buscado e ainda por algum tempo buscará uma reinvenção das estratégias de organização social e familiar, em uma reinvenção do cotidiano mutilado pelos afiados discursos e práticas desenvolvimentistas.

\section{REFERÊNCIAS}

BARBOSA, Alexandre de Freitas. O Bom e Velho Desenvolvimentismo. Disponível em: <https://teoriaedebate.org.br/2013/05/17/\%EF\%BB\%BFo-bom-e-velho-desenvolvimentismo/ $>$ Acesso em: 18 julho 2018.

BEZERRA, T. S. L.; HERRERA, J. A. As múltiplas transformações no território afetado pelo Empreendimento Hidrelétrico Belo Monte, na Amazônia Paraense. Revista do Instituto Histórico e Geográfico do Pará (IHGP), Belém, v. 04, n. 01, p. 267-278, jan./jun. 2017. Disponível em: http://www.ihgp.net.br/revista/index.php/revista/article/view/92. Acesso em: 24 agosto 2018.

CERTEAU, Michel de et al. A invenção do cotidiano: morar, cozinhar. $7^{\mathrm{a}}$ ed. Petrópolis: Vozes, 2008.

CONTINI, Elisio. A Colonização na Transamazônica: um enfoque analítico do plano governamental, seus resultados e problemas. Tese de Doutorado. 17/05/1976. FGV-Escola Brasileira de Administração Pública, 1976, p. 146-149. 
FICO, Carlos. Como eles agiam - os subterrâneos da ditadura militar. Espionagem e política. Rio de Janeiro: Record, 2001.

HERRERA, J. A. Desenvolvimento capitalista e realidade da produção agropecuária familiar na Amazônia Paraense. Tese/Doutorado. Campinas: Unicamp/IE, 2012. 365 f.

Resistência e Conflitos Sociais na Amazônia Paraense: a luta contra o empreendimento Hidrelétrico de Belo Monte. 2013. CAMPO-TERRITÓRIO: revista de geografia agrária, v. 8, n. 16, p. 130-151, ago., 2013. Disponível em: <http://www.seer.ufu.br/index.php/campoterritorio/article/view/19861>. Acesso em 25 de agosto 2018.

MORAES, Maria C. O Paradigma educacional emergente. Disponível em: <http://www.ub.edu/sentipensar/pdf/candida/paradigma_emergente.pdf> Acesso em: $10 \mathrm{de}$ maio de 2018.

MORIN, Edgar. Ciência com consciência. $8^{a}$ ed. - Rio de Janeiro: Bertrand Brasil, 2005.

UMBUZEIRO, Antônio Ubirajara Bogea. Altamira e sua história. Belém: Ponto Press, 2012.

WALKER, R.T.; HOMMA, A. K. O.; CONTO, A. J. de; CARVALHO, A. de A.; FERREIRA, C.A.P.; SANTOS. A.I.M. dos; ROCHA, A. C. P. N. da; OLIVEIRA. P. M. de; PREDRAZA, C. D. R. As contradições do processo de desenvolvimento agrícola na Transamazônica. Belém: Embrapa Amazônia Oriental, 1997. 